\title{
Treatment of Thyrotoxicosis with Low Doses of Radioactive Iodine
}

\author{
A. W. G. GOOLDEN,* M.B., D.M.R.T. ;T. RUSSELL FRASER, † M.D., F.R.C.P.
}

Cummary : In a series of 156 thyrotoxic patients treated $\checkmark$ with low doses of radioactive iodine the therapeutic dose was calculated by means of a sliding scale in which the dose level was varied according to the estimated size of the gland. Of the patients so treated $56.5 \%$ achieved a remission with a single dose of ${ }^{13} 1$ I. The incidence of hypothyroidism at one year was $5 \%$.

\section{Introduction}

One serious disadvantage of ${ }^{1: 31} \mathrm{I}$ therapy is the rising incidence of hypothyroidism with the passage of time. Beling and Einhorn (1961) first drew attention to this complication, and further reports have confirmed their original findings (Dunn and Chapman, 1964 ; Green and Wilson, 1964 ; McGirr et al., 1964 ; Greig et al., 1966 ; Nofal et al., 1966). Smith and Wilson (1967) showed that the incidence of hypothyroidism could be reduced by giving a smaller radiation dose to the thyroid. The lower radiation dose resulted in a higher proportion of patients who were still hyperthyroid after treatment, and these patients required additional treatment with an antithyroid drug. A substantial proportion of them subsequently achieved a remission on the antithyroid drug, which could then be discontinued. We adopted a somewhat similar scheme of treatment in 1965 .

\section{Methods}

\section{Preliminary Treatment with Antithyroid Drug}

Patients other than those with relatively mild thyrotoxicosis were given preliminary treatment with carbimazole for a period of 6 to 12 weeks. Pretreatment with this drug does not modify the response of thyrotoxic patients to subsequent treatment with ${ }^{131}$ I (Goolden and Fraser, 1969). Some patients from other hospitals had been maintained on an antithyroid drug for longer periods by the time they were referred for treatment. The antithyroid drug was discontinued 48 hours before a pretherapeutic test dose of ${ }^{131} \mathrm{I}$ was given. All patients selected for ${ }^{131} I$ therapy, including those with recurrent hyperthyroidism after thyroidectomy, were treated with a single dose of ${ }^{13}{ }^{1} \mathrm{I}$. The interval between stopping treatment with carbimazole and giving the therapeutic dose of ${ }^{131}$ I was from three to five days.

\section{Calculation of Dose}

The therapeutic dose was based on the 24-hour uptake following a test dose of ${ }^{13} \mathrm{I} I$ and the size of the gland estimated by palpation. The dose was calculated by means of a sliding scale in which the dose level was varied according to the size of the gland (see Table). For example, a patient having an uptake of $70 \%$ at 24 hours and a gland estimated to be $35 \mathrm{~g}$. would be treated at a dose level of $60 \mu \mathrm{Ci} / \mathrm{g}$. and would receive

$$
\frac{35 \times 60}{1,000} \times \frac{100}{70}=3.0 \mathrm{mCi}^{131} \mathrm{I}
$$

The radiation dose to the thyroid in this case would be about 3,500 rads.

* Consultant Radiotherapist, Hammersmith Hospital, London W.12.

t Professor of Clinical Endocrinology, Royal Postgraduate Medical School, London W.12.

\section{Follow-up}

All patients were seen at monthly intervals for the first three months after treatment. At three months thyroid function tests, including protein-bound iodine, T3-Sephadex uptake, and $T$ index, were carried out. Patients who on clinical grounds were suspected of being hypothyroid also had the serum cholesterol determined and an electrocardiogram taken. The effect of treatment with L-thyroxine on these criteria and on their clinical condition was taken into account in making the final assessment of thyroid status. Patients who had become euthyroid were seen thereafter at appropriate intervals and all were seen at one year after treatment. Those who were euthyroid at one year were subsequently seen at yearly intervals.

Patients who were still hyperthyroid after treatment were given carbimazole, usually $15 \mathrm{mg}$. a day initially, the dose later being reduced to $10 \mathrm{mg}$. daily. The drug was discontinued after a year or earlier if treatment seemed unnecessary. Patients who had been given an antithyroid drug after ${ }^{131} I$ therapy were not considered to be euthyroid until the drug had been stopped for at least six months. A second course of drug treatment was started if a relapse occurred. Patients who were still thyrotoxic after two courses of antithyroid drug therapy were subsequently treated according to individual circumstances. Some were continued on the antithyroid drug. A few were given a second therapeutic dose of ${ }^{131} \mathrm{I}$.

\section{Results}

The results obtained in 156 patients treated between April 1965 and April 1968 are shown in the Table. These are based on an assessment of thyroid status one year after ${ }^{131}$ I therapy. About two-thirds of the 60 patients who were still thyrotoxic and required treatment with an antithyroid drug after ${ }^{131} I$ therapy achieved a remission within two years. The remainder -that is, about $10 \%$ of the total number of patients treatedwere still thyrotoxic at the end of that time.

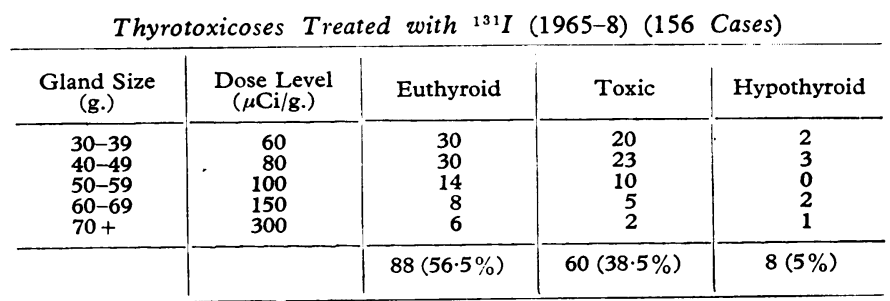

The incidence of hypothyroidism at one year with this regimen has fallen to $5 \%$. Two of the 88 patients who were euthyroid at one year have subsequently become hypothyroidone at two years and one at four years. The incidence of hypothyroidism at one year in a larger series of 564 patients treated at this hospital between 1950 and 1962 was $17 \%$.

\section{Discussion}

Before 1965 we calculated the therapeutic dose on the basis of $150 \mu \mathrm{Ci}^{131} \mathrm{I}$ per gramme of thyroid for all patients except 
those estimated to have glands weighing $70 \mathrm{~g}$. or more, who were treated at a dose level of $300 \mu \mathrm{Ci} / \mathrm{g}$. The results obtained with this regimen when analysed according to the size of the goitre showed that the proportion of patients who became hypothyroid was greatest in those with small goitres and became progressively less with increase in size of the goitre. The incidence of residual thyrotoxicosis, on the other hand, showed the reverse trend, being highest in patients with large goitres. These data suggested that a large thyroid gland required a larger radiation dose per gramme of tissue than a smaller gland. An alternative explanation might be that the tendency to underestimate size becomes greater with increase in size of the gland. In practical terms it seemed appropriate to use a dose level of ${ }^{131}$ I which varied according to the size of the gland.

An incidence of hypothyroidism of $5 \%$ at one year is probably acceptable, and it would seem impracticable to attempt to reduce it any further. The natural history of the disease suggests that a certain incidence of hypothyroidism is to be expected with any method of treatment, and the incidence after surgery is probably rather higher than is generally realized. Hedley et al. (1969), for instance, traced 150 patients treated surgically for thyrotoxicosis between 1946 and 1965, and found the total incidence of hypothyroidism to be $38 \%$. Nofal et al. (1966) estimated that $43 \%$ of surgically treated patients would become hypothyroid within 10 years of treatment.

Treatment for the patients who were still hyperthyroid after ${ }^{1: 31}$ I and two courses of treatment with carbimazole has clearly been unsatisfactory. In retrospect some alternative plan would have been preferable, but we cannot yet identify this small proportion of patients, about $10 \%$ of the total number treated, who eventually proved to be unresponsive to the combined method of treatment.

Hagen et al. (1967) compared high- and low-dosage levels in a series of thyrotoxic patients. In the low-dosage group, who were given a dose of $80 \mu \mathrm{Ci}{ }^{131} \mathrm{I}$ per estimated gramme of thyroid tissue, the incidence of hypothyroidism after a mean follow-up period of 19 months was $6 \%$. Our results with regard to the incidence of hypothyroidism are similar to those of Smith and Wilson (1967). They reduced the incidence of hypothyroidism to $4.3 \%$ in a group of patients given a radiation dose of 3,500 rads, though at this dosage level $65 \%$ of the patients were still toxic after one treatment. The cumulative incidence of hypothyroidism in their patients was $7.4 \%$ at five years. We are not able at this stage to estimate the cumulative incidence of hypothyroidism in the patients we have treated with low doses of radioactive iodine.

\section{Conclusions}

The method of treatment described here has effectively reduced the initial incidence of hypothyroidism. A dosage scheme in which the dosage level is related to thyroid size is probably more appropriate than a uniform dose level for all patients.

\section{REFERENCES}

Beling, U., and Einhorn, J. (1961). Acta Radiologica, 56, 275.

Dunn, J. T., and Chapman, E. M. (1964). New England fournal of

Medicine, 271, 1037.
Goolden, A. W. G., and Fraser, T. R. (1969). British Medical fournal, 3,443 .

Green, M., and Wilson, G. M. (1964). British Medical fournal, 1, 1005. Greig, W. R., Crooks, J., and Macgregor, A. G. (1966). Proceedings of the Royal Society of Medicine, 59, 599.

Hagen, G. A., Ouellette, R. P., and Chapman, E. M. (1967). New England Fournal of Medicine, 277, 559.

Hedley, A. J., Tulloch, M. I., Ross, I. P., Michie, W., Beck, J. S., and Crooks, J. (1969). Scottish Medical fournal. In press.

McGirr, E. M., Thompson, J. A., and Murray, I. P. C. (1964). Scottish Medical fournal, 9, 505 .

Nofal, M. M., Beierwaltes, W. H., and Patno, M. E. (1966). fournal of the American Medical Association 197, 605

Smith, R. N., and Wilson, G. M. (1967). British Medical fournal, 1, 129.

\title{
Effect of Pretreatment with Carbimazole in Patients with Thyrotoxicosis Subsequently Treated with Radioactive Iodine
}

\author{
A. W. G. GOOLDEN,* M.B., D.M.R.T. ; T. RUSSELL FRASER, † M.D., F.R.C.P.
}

British Medical fournal, 1969, 3, 443-444

Summary : Preliminary treatment with carbimazole in a $\checkmark$ series of 181 patients with thyrotoxicosis selected for treatment with radioactive iodine did not make any significant difference to the subsequent response to ${ }^{131} I$ therapy.

\section{Introduction}

One disadvantage of ${ }^{131}$ I therapy for thyrotoxicosis, particularly when low doses are used, is that the therapeutic effect is rather slow. In patients with severe thyrotoxicosis it is of ten desirable to control the disease as quickly as possible by means of an antithyroid drug. The remission rate, however, as judged by the proportion of patients who were cured by one dose of ${ }^{131} \mathrm{I}$,

* Consultant Radiotherapist, Hammersmith Hospital, London W.12. + Professor of Clinical Endocrinology, Royal Postgraduate Medical School
of London, London W.12. was lower in patients who had been previously treated with methylthiouracil (Crooks et al., 1960). It was concluded from these findings that pretreatment with methylthiouracil rendered the gland relatively radioresistant. Similar observations have been made in the case of propylthiouracil (Einhorn and Säterborg, 1962). For a number of years we had been using carbimazole to control thyrotoxicosis before ${ }^{131} \mathrm{I}$ therapy and it seemed advisable to find out whether this drug had a similar effect. The effect of pretreatment with carbimazole was accordingly investigated in patients who had been treated with ${ }^{131} I$ for thyrotoxicosis between 1960 and 1963.

\section{Methods}

Patients selected for ${ }^{131} \mathrm{I}$ therapy were divided into two groups according to whether or not they were given preliminary 